\title{
Endoscopic Features of Mucous Cap Polyps: A Way to Predict Serrated Polyps
}

\author{
Brian T. Moy ${ }^{1}$, Faripour Forouhar ${ }^{2}$, Chia-Ling Kuo ${ }^{3}$ and Thomas J. Devers ${ }^{1}$ \\ ${ }^{1}$ Division of Gastroenterology and Hepatology, ${ }^{2}$ Department of Pathology, ${ }^{3}$ Connecticut Institute for Clinical \& Translational Science, UConn \\ Health, Farmington, CT, USA
}

Background/Aims: The aims of the study were to identify whether a mucous-cap predicts the presence of serrated polyps, and to determine whether additional endoscopic findings predict the presence of a sessile serrated adenomas/polyp (SSA/P).

Methods: We analyzed 147 mucous-capped polyps with corresponding histology, during 2011-2014. Eight endoscopic features (presence of borders, elevation, rim of debris, location in the colon, size $\geq 10 \mathrm{~mm}$, varicose vessels, nodularity, and alteration in mucosal folds) of mucous-capped polyps were examined to see if they can predict SSA/Ps.

Results: A total of $86 \%(n=126)$ of mucous-capped polyps were from the right sided serrated pathway (right-sided hyperplastic [ $n=83$ ], SSA/Ps [ $n=43]$, traditional serrated adenoma $[n=1]), 10 \%(n=15)$ were left-sided hyperplastic polyps, and $3 \%(n=5)$ were from the adenoma-carcinoma sequence. The presence of a mucous cap combined with varicose vessels was the only significant predictor for SSA/Ps. The other seven characteristics were not found to be statistically significant for SSA/Ps, although location in the colon and the presence of nodularity trended towards significance.

Conclusions: Our study suggests that mucous-capped polyps have high predictability for being a part of the serrated pathway. Gastroenterologists should be alert for a mucous-capped polyp with varicose veins, as these lesions have a higher risk of SSA/P.

Clin Endosc 2018;51:368-374

Key Words: Sessile serrated adenoma; Mucous cap polyp; Serrated pathway; Colorectal neoplasms

\section{INTRODUCTION}

The effectiveness of colorectal cancer (CRC) screening is based on the adenoma-carcinoma sequence, ${ }^{1}$ in which genetic alterations in the tumor suppressor genes and oncogenes accumulate over time, underscoring the importance of their identification and removal. ${ }^{2,3}$ An alternative theory for the development of colon cancer has been described, known as the serrated adenoma pathway. This pathway involves accumulation of molecular mutations in the serrated adenomas, even-

Received: September 20, 2017 Revised: November 1, 2017

Accepted: November 20, 2017

Correspondence: Brian T. Moy

Division of Gastroenterology and Hepatology, UConn Health, 263 Farmington Ave, Farmington, CT 06030, USA

Tel: +1-860-679-3238, Fax: +1-860-679-3159, E-mail: moy@uchc.edu

ORCID: https://orcid.org/0000-0002-3388-3095

cc This is an Open Access article distributed under the terms of the Creative Commons Attribution Non-Commercial License (http://creativecommons.org/ licenses/by-nc/3.0) which permits unrestricted non-commercial use, distribution, and reproduction in any medium, provided the original work is properly cited. tually leading to CRC.,5 Torlakovic et al. showed evidence of abnormal proliferation in serrated polyps, which look similar to hyperplastic polyps (HPs), but could be differentiated as sessile serrated adenomas/polyps (SSA/Ps) on histology. ${ }^{6}$

Development of interval colon cancer shares certain features with SSA/Ps including proximal location, high level of microsatellite instability, and the hypothesis that these subtle lesions arise from serrated adenomas missed on routine colonoscopy. There is evidence that a subset of SSA/Ps is characterized by a brown-mucous cap, a distinct endoscopic feature that might be present in up to $60 \%$ of these lesions. ${ }^{7}$ It is unknown whether these mucous-capped SSA/Ps share molecular mutations with standard SSA/Ps, or represent a distinct clinical entity.

Screening colonoscopy is effective in reducing the overall rate of colon cancer, but has not been as effective in reducing right-sided colon cancers. In a population-based study, $6 \%$ of patients with newly discovered right-sided CRC had undergone colonoscopy 6 months to 3 years before the diag- 
nosis. ${ }^{8}$ Furthermore, Baxter et al. confirmed that screening colonoscopy was effective in reducing CRC-related mortality rates for left-sided disease, but was less effective in preventing death from right-sided CRC. ${ }^{9}$ One explanation for this is that right-sided mucous-capped lesions are often missed during colonoscopy. ${ }^{3}$ SSA/Ps are subtle polyps that appear similar to HPs and the diagnosis by endoscopists is often varied; thus, they are often not resected or incompletely resected. ${ }^{10-14}$ They are difficult to identify with suboptimal bowel preparation and their malignant potential is unknown. Bowel preparation is important for adenoma detection, especially for the identification of flat SSA/Ps on the right side. ${ }^{15-17}$

Few retrospective studies have described endoscopic characteristics of SSA/Ps. There is evidence that education and training of endoscopists would increase the diagnosis of these lesions. By identifying the typical the endoscopic features of SSA/Ps during colonoscopy, endoscopists could better manage polyps they encounter and potentially decrease the incidence and mortality of CRC, particularly in the right colon. ${ }^{18}$ We hypothesize that mucous-capped SSA/Ps represent an important group of commonly missed right-sided polyps. The goal of the study was to identify whether mucous-capped polyps predict the presence of polyps that were a part of the serrated pathway (right-sided HPs or SSA/Ps). Furthermore, endoscopic features of mucous-capped polyps (presence of borders, elevation, rim of debris, location in colon, size, varicose vessels, nodularity, and alteration in mucosal folds) were examined to determine if they could predict SSA/Ps. These observations could be used by endoscopists to improve endoscopic identification of SSA/Ps, which in turn can improve the detection of CRC. ${ }^{7}$

\section{MATERIALS AND METHODS}

The retrospective study was approved by the Institutional Review Board of the University Of Connecticut Health Center. High-definition (1080i signal wide-angle [170-degree field of view]) Olympus 180 series were used to perform all colonoscopies. ${ }^{19}$ The colon was classified into the right and left side, at the splenic flexure. ${ }^{19} \mathrm{~A}$ colonoscopy was considered complete if there was transillumination of the right lower quadrant, or visualization of the ileocecal valve or appendicular orifice. ${ }^{19}$ An experienced endoscopist (TJD) identified a mucous-capped polyp from the documentation of a representative group of adenomas. Mucous cap was defined as a focal collection of mucus (clear, bile-stained, or debris-stained) on the mucosal surface that can be removed with irrigation. ${ }^{14}$ All polyps were documented next to a snare catheter for in vivo measurement. ${ }^{19}$ We analyzed 147 mucous-capped pol- yps identified from 2,069 colonic polyps during 2011-2014. After a review of the literature, predefined criteria for each endoscopic feature were used to identify the mucous-capped polyps from previously taken pictures through retrospective chart review (Table 1). ${ }^{7}$ All images were collected in a database and eight features of the polyp were analyzed including presence of borders, elevation, rim of debris, location in colon, size, varicose vessels, nodularity, and alteration in mucosal folds. One observer (BTM) analyzed each polyp scoring a visual descriptor as absent or present. The observer was blinded to polyp histology during the analysis.

An SSA/P was diagnosed if it demonstrated histologic characteristics confirmed by experienced gastrointestinal (GI) pathologists and an image was available from endoscopy. ${ }^{7}$ 2010 WHO criteria for SSA/Ps were used, which included the following features: deep crypt serration with goblet cells, evidence of crypt base dilation, horizontal crypts at the polyp base with " $\mathrm{T}$ " or "boot shapes", and mild atypia with diffuse proliferative zone. ${ }^{7}$ In our approach, the presence of one crypt with most of the above features was deemed adequate to include the polyp in SSA category. Crypt herniation through the muscularis muscle was another inclusion criterion seen. The slides were interpreted by three pathologists specializing in GI pathology.

Inclusion criteria: Adults above 18 years, who had colorectal lesions during a screening colonoscopy without prior histologic diagnosis. Mucous-capped polyps identified by one endoscopist (TJD) during 2011-2014 were examined.

Exclusion criteria: Medical history or a diagnosis of inflammatory bowel disease, more than two mucous-capped polyps identified in the same patient, serrated polyposis syndrome, familial adenomatous polyposis, Lynch syndrome, patients with inadequate bowel preparation, or incomplete colonos-

Table 1. Individual Endoscopic Descriptors for Sessile Serrated Adenomas

\begin{tabular}{|c|c|}
\hline Distinct borders & $\begin{array}{l}\text { Demarcation of a subtle or focal border } \\
\text { around a lesion }\end{array}$ \\
\hline Elevation & $\begin{array}{l}\text { Lesions have a rounded apex and is }>50 \% \\
\text { as high as it is wide }\end{array}$ \\
\hline Rim of debris & $\begin{array}{l}\text { Unique ring of debris/bubble encircling } \\
>25 \% \text { of lesion }\end{array}$ \\
\hline Location in colon & Proximal to splenic flexure \\
\hline Size & Greater than or equal $10 \mathrm{~mm}$ \\
\hline Varicose vessels & $\begin{array}{l}\text { Small, curved, or linear vessels seen near } \\
\text { the surface of the lesion under the mu- } \\
\text { cous cap }\end{array}$ \\
\hline Nodular surface & Irregular or bumpy mucosal surface \\
\hline Alters fold contour & Lesion lays over a mucosal fold \\
\hline
\end{tabular}

Reproduced with permission from Elsevier Publishing.? 
copies were excluded from the study. If there was a mix in pathology with adenomatous polyp and SSPs, the polyp was excluded.?

\section{Statistical analysis}

The study's primary endpoint was identifying endoscopic features of mucous-capped polyps that can predict SSA/Ps. A secondary endpoint looked at the incidence of serrated polyps (right-sided hyperplastic, SSA/Ps, or traditional serrated adenomas [TSAs]) when a mucous cap was present. Each variable was descriptively summarized by mean, standard deviation of a continuous variable, frequency, and percentages of a categorical variable. A generalized linear mixed effects model with logit link was used to model SSA/Ps assuming different random intercepts for each patient. SSA/Ps were associated with each endoscopic predictor with and without adjustment for other predictors: polyp size $\geq 10 \mathrm{~mm}$ (Present/Absent), distinct borders (Present/Absent), elevation (Present/Absent), rim of debris (Present/Absent), location in colon (Present/Absent), varicose vessels (Present/Absent), nodularity (Present/Absent), alteration in mucosal folds (Present/Absent). The unadjusted and adjusted odds ratios along with their $95 \%$ confidence intervals were reported. A $p$-value smaller than $5 \%$ was considered statistically significant.

All the statistical analyses were performed in R 3.3.1 (ref). R Core Team (2016). R: A language and environment for statistical computing. R Foundation for Statistical Computing, Vienna, Austria. https://www.R-project.org/.

\section{RESULTS}

\section{Polyp characteristics}

A total of 147 mucous-capped polyps were identified from 2,069 colonic polyps, during 2011-2014. During the 4-year study period, $7.1 \%$ of all examined polyps contained a mucous cap. Twenty-one patients had 2-mucous capped polyps identified. Thus, all polyp characteristics were considered from 126 patients who underwent colonoscopies at a single tertiary referral center. Overall, the average polyp size was $8.23 \mathrm{~mm}$. The average size of an SSA/P was $8.84+/-4.23 \mathrm{~mm}$ while size of a non-SSA/P was $7.62+/-3.00 \mathrm{~mm}$. Majority of the polyps $(n=100)$ were in the range of $6-10 \mathrm{~mm}$ (Table 2). One hundred and thirty-two mucous-capped polyps were right sided (Table 2).

\section{Mucous cap and association with the serrated path- way}

In the primary analysis, presence of a mucous cap and its association with being a serrated polyp were studied. $86 \%$
( $n=126)$ of mucous-capped polyps were from the right sided serrated pathway (right-sided hyperplastic [ $n=83]$, SSA/Ps [ $n=43]$, TSA [ $n=1]), 10 \%(n=15)$ were left-sided HPs, and $3 \%$ $(n=5)$ were from the adenoma-carcinoma sequence (Figs. 1-4, Table 3). None of the SSA/Ps had cancer or high-grade dysplasia.

\section{Mucous cap with endoscopic features predicting SSA/P histology}

Endoscopic predictors of SSA/Ps are described in Table 3. SSA/Ps with a mucous cap were over $10 \mathrm{~mm}$ in $35 \%$ of samples, the presence of distinct borders was observed in $81 \%$, elevation in $70 \%$, a rim of debris in $98 \%$, were right sided in $95 \%$, had varicose vessels in $91 \%$, nodularity in $35 \%$, and alteration in mucosal folds in $60 \%$ of all samples confirmed SSA/Ps by histology. The unadjusted and adjusted results were consistent (Table 3). The presence of a mucous cap combined with varicose vessels was the only statistically significant predictor for SSA/Ps. The adjusted odds ratio was 10.75 with $95 \%$ confidence interval $(3.34,34.61)$. Polyp size $\geq 10 \mathrm{~mm}$, nodular-

Table 2. Size, Location, and Histology of Mucous-Capped Polyps

\begin{tabular}{|c|c|}
\hline $\begin{array}{l}\text { Size of mucous-capped polyps } \\
(\mathrm{mm})\end{array}$ & $\begin{array}{l}\text { No. of mucous capped polyps } \\
\qquad(n=147)\end{array}$ \\
\hline $0-5$ & 28 \\
\hline $6-10$ & 100 \\
\hline $11-15$ & 15 \\
\hline $16-20$ & 2 \\
\hline $21-25$ & 2 \\
\hline$>26$ & 0 \\
\hline $\begin{array}{l}\text { Location of mucous-capped } \\
\text { polyps }\end{array}$ & $\begin{array}{l}\text { No. of mucous capped polyps } \\
\qquad(n=147)\end{array}$ \\
\hline Cecum & 18 \\
\hline Ascending colon & 104 \\
\hline Transverse colon & 10 \\
\hline Descending colon & 9 \\
\hline Sigmoid colon & 6 \\
\hline Rectum & 0 \\
\hline $\begin{array}{l}\text { Histology of mucous-capped } \\
\text { polyps }\end{array}$ & $\begin{array}{c}147 \text { Mucous Capped Polyps } \\
(\%)\end{array}$ \\
\hline $\mathrm{SSA} / \mathrm{P}$ & $43(29 \%)$ \\
\hline Right sided HP & $83(56 \%)$ \\
\hline $\begin{array}{l}\text { Right sided serrated polyp } \\
\text { (right sided HP or SSA) }\end{array}$ & $126(86 \%)$ \\
\hline Left sided HP & $15(10 \%)$ \\
\hline Tubular adenoma & $5(3 \%)$ \\
\hline Traditional serrated adenoma & $1(0.7 \%)$ \\
\hline
\end{tabular}

SSA/P, sessile serrated adenomas/polyp; HP, hyperplastic polyp. 
ity, elevation, distinct borders, location in the colon, alteration in mucosal folds, and rim of debris were negatively associated with the polyp being an SSA/P, although they did not reach statistical significance $(p \leq 0.05)$. Location in the colon and the presence of nodularity trended towards significance and predicted an increase the risk of SSA/P by 4.43 and 2.39 times, respectively. The wide confidence intervals suggest heterogeneity among patients, which might be explained by different patient characteristics. Patient characteristics such as demographic variables were not collected in our study.

\section{DISCUSSION}

Colonoscopies have been used to detect and resect adenomatous polyps to prevent CRCs. ${ }^{7}$ During the past decade, clinical experience and new insights have drawn attention to the serrated pathway, which can transform serrated non-dysplastic lesions into unstable cancers. ${ }^{7}$ Serrated polyps can be divided into three distinct subtypes, HPs, TSAs, and SSA/Ps, each with different molecular and clinical features.

HPs account for $80 \%-90 \%$ of serrated polyps. ${ }^{20}$ HPs are defined as elongated crypts with serrated architecture in the top half of the crypts. ${ }^{21}$ Histology reveals epithelial dysplasia with serration of the crypt luminal surface. The luminal portion of a polyp has a "saw tooth" appearance. ${ }^{22} \mathrm{HPs}$ can be categorized into microvesicular HPs (MVHPs), goblet-cell rich HPs (GCHPs), and mucin poor HPs. MVHPs are located on the right side of the colon and GCHPs are found on the left side of the colon. ${ }^{23}$ Differentiating between MVHPs and SSA/Ps is necessary in preventing interval cancer. ${ }^{23-27}$ These cells typically lack dysplasia and the potential to develop into cancer. ${ }^{20}$ GCHPs were found to be 3- to 5-mm sessile lesions that are pale, multiple, and located in the left colon at the rectosigmoid area. ${ }^{20}$ Size $>5 \mathrm{~mm}$ or right-sided lesions should raise the possibility of an SSA/P or MVHPs. ${ }^{22}$

SSA/Ps were first described by Fengolio-Presier. ${ }^{20}$ SSA/Ps account for $5.8 \%-7.5 \%$ of all colorectal carcinomas and $17.5 \%$ of proximal colon cancers. ${ }^{22,28}$ Previous endoscopic features for SSA/Ps described in the literature with a predictive potential for SSA/Ps include indistinct borders with vague demarcation, mucous cap, disruption of a fold, rim of debris, dome-like distribution, dark spots inside the crypts, cloud-like surface featuring a nodular surface resembling a cumulus cloud, and irregular shape with asymmetry. ${ }^{29}$ The SSA/Ps are found primarily in the cecum or proximal ascending colon, which were the focus of this study. Although, SSA/Ps have a right-sided predominance, they can appear in the rectosigmoid area and are often left in situ because of their benign "hyperplastic" appearance. ${ }^{29}$ The oversight of SSA/Ps during screening colonos-
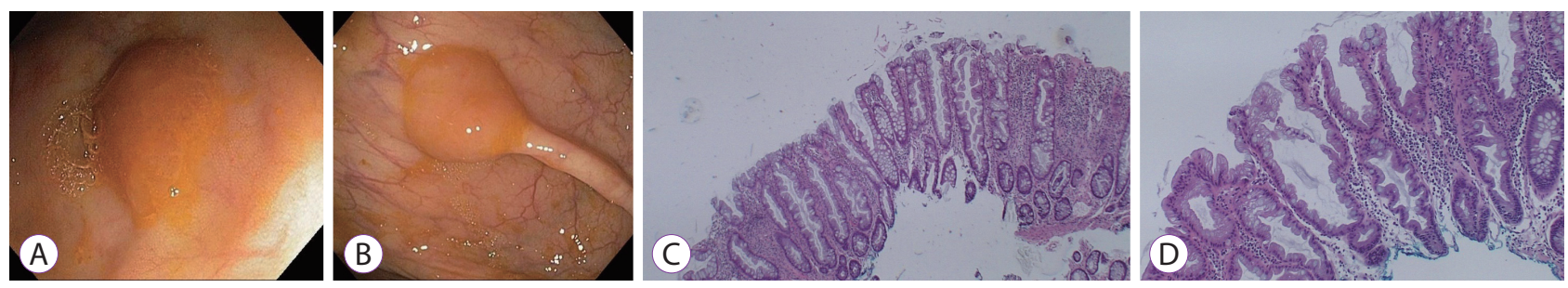

Fig. 1. (A) An $8 \mathrm{~mm}$ mucous-capped polyp in the ascending colon with a distinct border, elevation, and rim of debris. The polyp is $\leq 10 \mathrm{~mm}$, without varicose vessels, nodular surface, and altering contour folds. The histology is a hyperplastic polyp. (B) A 15 mm mucous-capped polyp in the ascending colon with size $\geq 10 \mathrm{~mm}$, a distinct border, elevation, rim of debris, and altering contour folds. The polyp is without varicose vessels and a nodular surface. The histology is a hyperplastic polyp. (C) The histology on hematoxylin and eosin (H\&E) stain is a hyperplastic polyp. The crypts are elongated but straight, narrow, and hyperchromatic with an ordinary base ( $\times 40)$. (D) The histology on H\&E stain is a hyperplastic polyp $(\times 100)$.
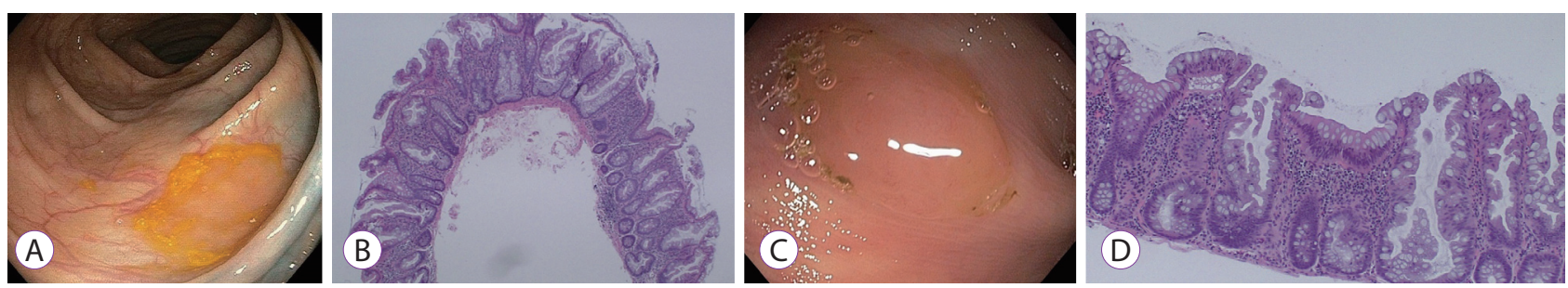

Fig. 2. (A) A $25 \mathrm{~mm}$ mucous-capped polyp in the ascending colon with size $\geq 10 \mathrm{~mm}$, a distinct border, varicose vessels, and nodular surface. The polyp is without elevation, altering contour fold, and rim of debris. The histology is an sessile serrated adenomas/polyp (SSA/P). (B) The histology on hematoxylin and eosin (H\&E) stain is an SSA/P. Disorganized, markedly dilated crypts showing extension of goblet cells to the base, and sideways growth of the crypt base is shown ( $\times 40$ ). (C) A $6 \mathrm{~mm}$ mucous-capped polyp in the ascending colon with distinct borders, rim of debris, and varicose vessels. The size of the polyp is $\leq 10 \mathrm{~mm}$, without a nodular surface, and altering contour fold. The histology is an SSA/P. (D) The histology on H\&E stain is an SSA/P. Disorganized, markedly dilated crypts showing extension of goblet cells to the base, and sideways growth of the crypt base is shown $(\times 100)$. 

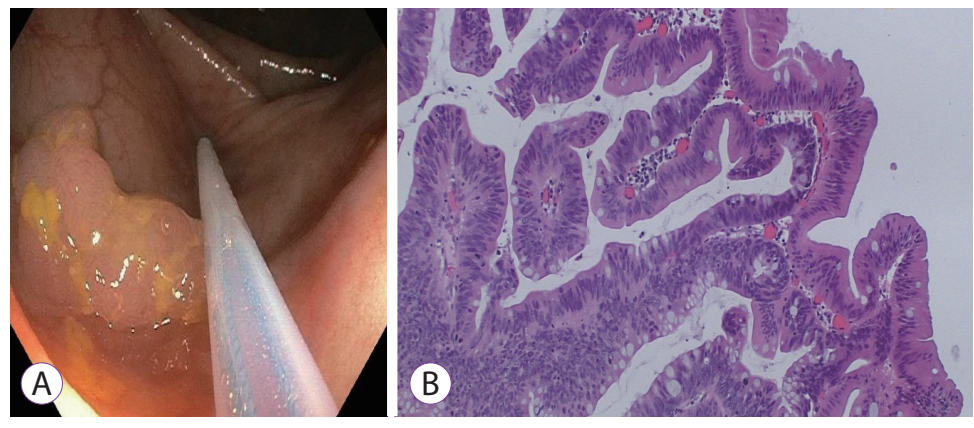

Fig. 3. (A) A $15 \mathrm{~mm}$ mucous-capped polyp in ascending colon with size $\geq 10 \mathrm{~mm}$, distinct border, elevation, varicose vessels, and nodular surface. The polyp is without a rim of debris and doesn't alter contour folds. The histology is a traditional serrated adenoma (TSA). (B) Features of a TSA on hematoxylin and eosin stain show low grade dysplasia with serration separating it from an ordinary tubular adenoma. Note the presence of an eosinophilic cytoplasm of the surface epithelial columnar cells $(\times 200)$.
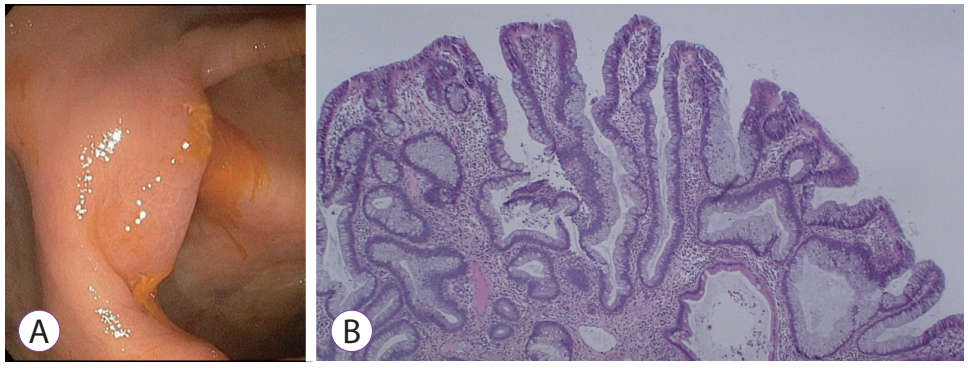

Fig. 4. (A) A $12 \mathrm{~mm}$ mucous-capped polyp in cecum with size $\geq 10$ $\mathrm{mm}$, distinct border, elevation, varicose vessels, nodular surface, and altering contour folds. The polyp is without a rim of debris. The histology is a tubular adenoma. (B) Tubular Adenoma is shown on hematoxylin and eosin stain $(\times 100)$.

Table 3. Descriptive and Association Analyses of Endoscopic Characteristics of Mucous Cap Polyps

\begin{tabular}{|c|c|c|c|c|c|c|c|}
\hline \multirow[b]{2}{*}{ Predictor } & \multicolumn{3}{|c|}{ Mean \pm SD or frequency (\%) } & \multicolumn{2}{|c|}{ Unadjusted } & \multicolumn{2}{|c|}{ Adjusted } \\
\hline & $\begin{array}{c}\mathrm{SSA} / \mathrm{P}+ \\
(n=43)\end{array}$ & $\begin{array}{l}\text { SSA/P- } \\
(n=104)\end{array}$ & $\begin{array}{c}\text { Total } \\
(n=147)\end{array}$ & $\begin{array}{c}\text { OR } \\
(95 \% \mathrm{CI})\end{array}$ & $p$-value & $\begin{array}{c}\text { OR } \\
(95 \% \mathrm{CI})\end{array}$ & $p$-value \\
\hline $\begin{array}{l}\text { Polyp size } \geq 10 \mathrm{~mm} \\
\quad \text { (Present) }\end{array}$ & $15(35 \%)$ & $29(28 \%)$ & $44(30 \%)$ & $\begin{array}{c}1.39 \\
(0.65,2.96)\end{array}$ & 0.4 & $\begin{array}{c}1.57 \\
(0.65,3.82)\end{array}$ & 0.320 \\
\hline $\begin{array}{l}\text { Distinct Borders } \\
\text { (Present) }\end{array}$ & $35(81 \%)$ & $80(77 \%)$ & $115(78 \%)$ & $\begin{array}{c}1.31 \\
(0.54,3.21)\end{array}$ & 0.551 & $\begin{array}{c}2.54 \\
(0.64,10.09)\end{array}$ & 0.184 \\
\hline Elevation (Present) & $30(70 \%)$ & $73(70 \%)$ & $103(70 \%)$ & $\begin{array}{c}0.98 \\
(0.45,2.13)\end{array}$ & 0.959 & $\begin{array}{c}0.39 \\
(0.11,1.43)\end{array}$ & 0.157 \\
\hline $\begin{array}{l}\text { Rim of debris } \\
\text { (Present) }\end{array}$ & $42(98 \%)$ & $93(89 \%)$ & $135(92 \%)$ & $\begin{array}{c}4.97 \\
(0.62,39.73)\end{array}$ & 0.131 & $\begin{array}{c}4.76 \\
(0.50,45.51)\end{array}$ & 0.176 \\
\hline $\begin{array}{l}\text { Location in Colon } \\
\quad \text { (Present) }\end{array}$ & $41(95 \%)$ & $91(88 \%)$ & $132(90 \%)$ & $\begin{array}{c}2.93 \\
(0.63,13.57)\end{array}$ & 0.170 & $\begin{array}{c}4.90 \\
(0.94,25.62)\end{array}$ & 0.060 \\
\hline $\begin{array}{l}\text { Varicose Vessels } \\
\quad \text { (Present) }\end{array}$ & $39(91 \%)$ & $56(54 \%)$ & $95(65 \%)$ & $\begin{array}{c}8.36 \\
(2.79,25.08)\end{array}$ & 0.000 & $\begin{array}{c}10.75 \\
(3.34,34.61)\end{array}$ & 0.000 \\
\hline $\begin{array}{l}\text { Nodular surface } \\
\text { (Present) }\end{array}$ & $15(35 \%)$ & $23(22 \%)$ & $38(26 \%)$ & $\begin{array}{c}1.89 \\
(0.87,4.11)\end{array}$ & 0.110 & $\begin{array}{c}2.43 \\
(0.93,6.31)\end{array}$ & 0.069 \\
\hline $\begin{array}{l}\text { Alters fold contour } \\
\quad \text { (Present) }\end{array}$ & $26(60 \%)$ & $52(50 \%)$ & $78(53 \%)$ & $\begin{array}{c}1.53 \\
(0.74,3.15)\end{array}$ & 0.249 & $\begin{array}{c}1.48 \\
(0.60,3.66)\end{array}$ & 0.398 \\
\hline
\end{tabular}

SD, standard deviation; SSA/P, sessile serrated adenomas/polyp; OR, odds ratio; $\mathrm{CI}$, confidence interval.

copy due to their morphology (flat or sessile), color (similar to the surrounding mucosa), and the endoscopists' unfamiliarity with these lesions are the factors for the incidence of CRC in the right colon not decreasing. ${ }^{18}$ Because of their similarity to HPs, it is reasonable to think that many of these polyps are left in situ when they are misinterpreted by endoscopists. ${ }^{29}$ Detecting SSA/Ps is at times more difficult to identify than adenomatous polyps on colonoscopy, because SSA/Ps are often pale, flat, and endoscopists might be less aware of their appearance and relevance. ${ }^{7}$

SSA/Ps are characterized by serration, distorted crypt dilatation ("L, inverted T, hockey stick or boot"), horizontally extended crypt bases, and nuclear changes that are not dysplastic. ${ }^{21,22}$ WHO criteria require one unequivocal crypt with 
features characteristic of an SSA/P. The epithelial cells around SSA/Ps have enlarged cytoplasm with microvesicular mucin leading to the formation of a mucous-capped polyp. This epithelium has the potential to undergo dysplastic mutation and lead to invasive adenocarcinoma.

Torlakovic et al. proposed that mucous caps have a higher risk for SSA/Ps, because mucous excretion results in the absorptive epithelium to be pushed towards the stromal area leading to a dilated pit opening. ${ }^{6,30}$ Tadepalli et al. specifically compared SSA/Ps $(n=158)$ and adenomatous polyps $(n=40){ }^{7}$ Approximately $65 \%(n=103)$ of SSA/Ps were found to have a mucous cap. This is the first study to analyze if mucous-capped polyps in combination with other endoscopic characteristics previously defined in the literature, have better predictability for identifying SSA/Ps under standard white light endoscopy (WLE).

In our study, we identified varicose vessels along with the presence of a mucous cap as being a predictor for SSA/Ps. In prior studies, varicose vessels were defined as a positive visual descriptor for $32.3 \%(n=51)$ of SSA/Ps analyzed. ${ }^{7,31}$ One theory is that SSA/Ps alter the contour of the mucosal folds and one-third of polyps develop changes in the underlying vascular pattern. ${ }^{7}$ A darker vascular pattern might correlate with neoplasia, while a normal or lighter pattern might suggest a non-neoplastic pattern. ${ }^{29,32}$ Uraoka et al. showed that the presence of varicose vessels had higher specificity at $87.8 \%$, but lower sensitivity at $57.9 \%$ for identifying SSA/Ps. ${ }^{31}$ In a study by Yamashina et al., expanded crypt opening or thickbranched vessels were seen in 50/51 SSA/Ps. ${ }^{33}$ Expanded crypt openings were seen in 43/51 SSA/Ps and thick-branched vessels were seen in 23/51 of SSA/Ps. ${ }^{33}$ Angiogenesis is important for malignant cells to proliferate. It seems plausible to suggest vascular morphology as a predictor for transformation to a malignant phenotype. ${ }^{31}$

The strengths of this study include the large number of mucous capped polyps identified ( $n=147)$, and the systematic approach to identify endoscopic features of mucous capped polyps that can predict SSA/Ps, which were not looked at in prior studies. The features looked at, are easy to assess with a regular colonoscope, making these details practical during routine colonoscopy. ${ }^{29}$ The results from this study can be extrapolated to the general population without high-risk conditions like serrated polyposis syndrome. ${ }^{29}$ Another strength of the study was that the observer who analyzed the characteristics of each polyp was blind to the final histology, to avoid an observer bias. Furthermore, having one endoscopist analyze/ resect all mucous-capped polyps helped limit inter-observer variability.

Narrow band imaging (NBI), chromoendoscopy, and magnification are the technologies available in recent years, which allow for better visualization during endoscopy. Several studies have reported using this technology to help identify predictive endoscopic characteristics of SSA/Ps. ${ }^{7,29,31}$ In a study by Hazewinkel et al., four features were found to be associated with SSA/Ps histology including a cloud-like surface on both high resolution WLE and NBI. ${ }^{29}$ On NBI, indistinctive borders, dark spots, and an irregular shape were found to be statistically significant for the detection of SSA/PS. ${ }^{29}$ Tadepalli et al. showed that NBI increased the visibility of SSA/Ps but there were no statistically specific findings displaying the effectiveness of NBI. ${ }^{7,31}$ They reported that using NBI to detect SSA/Ps has not increased polyp detection. ${ }^{7}$ Hazewinkel et al. showed a cloud surface, indistinct borders, different shapes, and dark spots enhanced by NBI in more than half of SSA/Ps looked at. ${ }^{29,31}$

The limitations of the study include use of still images as opposed to video clips, which give a more dynamic analysis in characterizing the appearance of SSPs. Appearance of the polyp might change with the angle, illumination, distension of the colon, or with movement of fluid/debris throughout the colon. The analysis of each polyp is subject to the quality of image taken. Another limitation was that it was a single center study and the histologic analysis was performed by three pathologists. With three pathologists analyzing the histology, there might be interobserver variation among experts in the diagnosis of SSA/Ps. Despite this drawback, this mimics real life practice in many clinical settings. More prospective randomized studies are necessary for further validation.

Accurate differentiation of these endoscopic features can help immediate decisions, rather than wait for pathologic analysis. ${ }^{29}$ Adequate recognition of SSA/Ps might help endoscopists in selecting a polypectomy technique that will ensure complete removal of the polyp with a lower risk technique. ${ }^{29}$ Ideally, all detected lesions should be resected, but in practice, endoscopists might not resect benign appearing right-sided polyps in the colon due to time, risks of the procedure, and costs. ${ }^{29}$ The endoscopic appearance of serrated polyps might not adequately predict the type of histology, thus non-resection of the polyp would preclude the visibility of what cellular transformation might be occurring on the serrated pathway or adenoma-carcinoma sequence. Furthermore, the strategy of "resect and discard" diminutive lesions to control costs has been proposed. ${ }^{31}$ Further studies looking at high risk features of mucous-capped polyps might help an endoscopist decide on complete resection versus removing polyps that appear hyperplastic with lower risk techniques, versus discarding polyps in real time. ${ }^{29}$

In conclusion, our study suggests that mucous-capped polyps have high predictability in being a part of the serrated pathway. Additionally, brown mucous-capped polyps have 
unique characteristics that can be identified during routine standard WLE. Gastroenterologists should be on alert if a mucous-capped polyp has varicose veins as these lesions have a higher risk of being an SSA/Ps. Increased awareness of these findings might improve the detection rates of serrated polyps, promote complete resection of these lesions, and ultimately reduce the rates of interval CRC. ${ }^{14}$

\section{Conflicts of Interest}

The authors have no financial conflicts of interest.

\section{Author Contributions}

Conceptualization: Brian T. Moy, Faripour Forouhar, Thomas J. Devers Data Curation: BTM

Formal Analysis: BTM, Chia-Ling Kuo

Supervision: TJD

Writing-original draft: BTM

Writing-review\&editing: BTM

\section{REFERENCES}

1. Vogelstein B, Fearon ER, Hamilton SR, et al. Genetic alterations during colorectal-tumor development. N Engl J Med 1988;319:525-532.

2. Sillars-Hardebol AH, Carvalho B, van Engeland M, Fijneman RJ, Meijer GA. The adenoma hunt in colorectal cancer screening: defining the target. J Pathol 2012;226:1-6.

3. East JE, Saunders BP, Jass JR. Sporadic and syndromic hyperplastic polyps and serrated adenomas of the colon: classification, molecular genetics, natural history, and clinical management. Gastroenterol Clin North Am 2008;37:25-46, v.

4. Arnold CA, Montgomery E, Iacobuzio-Donahue CA. The serrated pathway of neoplasia: new insights into an evolving concept. Diagn Histopathol (Oxf) 2011;17:367-375.

5. Leggett $B$, Whitehall V. Role of the serrated pathway in colorectal cancer pathogenesis. Gastroenterology 2010;138:2088-2100.

6. Torlakovic E, Skovlund E, Snover DC, Torlakovic G, Nesland JM. Morphologic reappraisal of serrated colorectal polyps. Am J Surg Pathol 2003;27:65-81.

7. Tadepalli US, Feihel D, Miller KM, et al. A morphologic analysis of sessile serrated polyps observed during routine colonoscopy (with video). Gastrointest Endosc 2011;74:1360-1368.

8. Bressler B, Paszat LF, Chen Z, Rothwell DM, Vinden C, Rabeneck L. Rates of new or missed colorectal cancers after colonoscopy and their risk factors: a population-based analysis. Gastroenterology 2007;132:96102

9. Baxter NN, Goldwasser MA, Paszat LF, Saskin R, Urbach DR, Rabeneck L. Association of colonoscopy and death from colorectal cancer. Ann Intern Med 2009;150:1-8.

10. Hetzel JT, Huang CS, Coukos JA, et al. Variation in the detection of serrated polyps in an average risk colorectal cancer screening cohort. Am J Gastroenterol 2010;105:2656-2664.

11. de Wijkerslooth TR, Stoop EM, Bossuyt PM, et al. Differences in proximal serrated polyp detection among endoscopists are associated with variability in withdrawal time. Gastrointest Endosc 2013;77:617-623.

12. Kahi CJ, Hewett DG, Norton DL, Eckert GJ, Rex DK. Prevalence and variable detection of proximal colon serrated polyps during screening colonoscopy. Clin Gastroenterol Hepatol 2011;9:42-46.

13. Pohl H, Srivastava A, Bensen SP, et al. Incomplete polyp resection during colonoscopy-results of the complete adenoma resection (CARE) study. Gastroenterology 2013;144:74-80.e1.

14. Murakami T, Sakamoto N, Ritsuno H, et al. Distinct endoscopic characteristics of sessile serrated adenoma/polyp with and without dysplasia/ carcinoma. Gastrointest Endosc 2017;85:590-600.

15. Parente F, Marino B, Crosta C. Bowel preparation before colonoscopy in the era of mass screening for colo-rectal cancer: a practical approach. Dig Liver Dis 2009;41:87-95.

16. Chiu HM, Lin JT, Lee YC, et al. Different bowel preparation schedule leads to different diagnostic yield of proximal and nonpolypoid colorectal neoplasm at screening colonoscopy in average-risk population. Dis Colon Rectum 2011;54:1570-1577.

17. Harewood GC, Sharma VK, de Garmo P. Impact of colonoscopy preparation quality on detection of suspected colonic neoplasia. Gastrointest Endosc 2003;58:76-79.

18. Pereyra L, Gómez EJ, González R, et al. Finding sessile serrated adenomas: is it possible to identify them during conventional colonoscopy? Dig Dis Sci 2014;59:3021-3026.

19. Rustagi T, Rangasamy P, Myers M, et al. Sessile serrated adenomas in the proximal colon are likely to be flat, large and occur in smokers. World J Gastroenterol 2013;19:5271-5277.

20. Bauer VP, Papaconstantinou HT. Management of serrated adenomas and hyperplastic polyps. Clin Colon Rectal Surg 2008;21:273-279.

21. Zhu H, Zhang G, Yi X, et al. Histology subtypes and polyp size are associated with synchronous colorectal carcinoma of colorectal serrated polyps: a study of 499 serrated polyps. Am J Cancer Res 2015;5:363-374.

22. Rex DK, Ahnen DJ, Baron JA, et al. Serrated lesions of the colorectum: review and recommendations from an expert panel. Am J Gastroenterol 2012;107:1315-1329; quiz 1314, 1330.

23. Saito S, Tajiri H, Ikegami M. Serrated polyps of the colon and rectum: endoscopic features including image enhanced endoscopy. World J Gastrointest Endosc 2015;7:860-871.

24. Mäkinen MJ. Colorectal serrated adenocarcinoma. Histopathology 2007;50:131-150.

25. Carr NJ, Mahajan H, Tan KL, Hawkins NJ, Ward RL. Serrated and non-serrated polyps of the colorectum: their prevalence in an unselected case series and correlation of BRAF mutation analysis with the diagnosis of sessile serrated adenoma. J Clin Pathol 2009;62:516-518.

26. Kim KM, Lee EJ, Ha S, et al. Molecular features of colorectal hyperplastic polyps and sessile serrated adenoma/polyps from Korea. Am J Surg Pathol 2011;35:1274-1286.

27. Spring KJ, Zhao ZZ, Karamatic R, et al. High prevalence of sessile serrated adenomas with BRAF mutations: a prospective study of patients undergoing colonoscopy. Gastroenterology 2006;131:1400-1407.

28. Gurudu SR, Heigh RI, De Petris G, et al. Sessile serrated adenomas: demographic, endoscopic and pathological characteristics. World J Gastroenterol 2010;16:3402-3405.

29. Hazewinkel Y, López-Cerón M, East JE, et al. Endoscopic features of sessile serrated adenomas: validation by international experts using high-resolution white-light endoscopy and narrow-band imaging. Gastrointest Endosc 2013;77:916-924.

30. Nakao Y, Saito S, Ohya T, et al. Endoscopic features of colorectal serrated lesions using image-enhanced endoscopy with pathological analysis. Eur J Gastroenterol Hepatol 2013;25:981-988.

31. Uraoka T, Higashi R, Horii J, et al. Prospective evaluation of endoscopic criteria characteristic of sessile serrated adenomas/polyps. J Gastroenterol 2015;50:555-563.

32. East JE, Suzuki N, Bassett $P$, et al. Narrow band imaging with magnification for the characterization of small and diminutive colonic polyps: pit pattern and vascular pattern intensity. Endoscopy 2008;40:811-817.

33. Yamashina T, Takeuchi Y, Uedo N, et al. Diagnostic features of sessile serrated adenoma/polyps on magnifying narrow band imaging: a prospective study of diagnostic accuracy. J Gastroenterol Hepatol 2015;30:117-123. 